\title{
Evaluation of the Changes in Vessel Density and Retinal Thickness in Patients Who Underwent Unilateral Congenital Cataract Extraction by OCTA
}

This article was published in the following Dove Press journal:

Clinical Ophthalmology

\begin{abstract}
Weiwei Zhang ${ }^{1} *$
Huan $\mathrm{Hu}^{2}$,*

Haixia Cheng (D) $^{3, *}$

Qinghuai Liu'

Dongqing Yuan (D)

'Department of Ophthalmology, The First Affiliated Hospital with Nanjing Medical University, Nanjing, Jiangsu Province, People's Republic of China; ${ }^{2}$ Department of Ophthalmology, Xishui People's Hospital Affiliated to Hubei University of Science and Technology, Huanggang, Hubei Province, People's Republic of China; ${ }^{3}$ Department of Ophthalmology, Children's Hospital of Nanjing Medical University, Nanjing, Jiangsu Province, People's Republic of China
\end{abstract}

*These authors contributed equally to this work
Correspondence: Dongqing Yuan Department of Ophthalmology, The First Affiliated Hospital of Nanjing Medical University, 300 Guangzhou Road, Nanjing, Jiangsu Province 210029, People's

Republic of China

$\mathrm{Tel} / \mathrm{Fax}+86-25-68303160$

Email wuyuleng@I26.com
Purpose: To evaluate the changes in vessel density in patients with unilateral congenital cataract after cataract extraction.

Materials and Methods: Children with unilateral congenital cataract were enrolled in our study. All of the patients underwent congenital cataract extraction and intraocular lens (IOL) implantation successfully. Optical coherence tomography angiography (OCTA) was performed to image the retinal vasculature in the macular and optic disc areas before and after surgery. The differences in vessel density and retinal thickness between groups were compared.

Results: We found that the best corrected visual acuity (BCVA) was significantly improved one month after surgery compared with that before surgery $(\mathrm{t}=5.179, \mathrm{p}<0.001)$. The axial length was also changed one month after surgery $(t=5.350, p<0.001)$. The vessel density in the macular and optic disc areas of the affected eyes was significantly lower than that in the normal eyes, while the vessel density at the posterior pole was significantly improved one month after cataract extraction.

Conclusion: The decrease in vessel density in the macular and optic disc areas might be a consequence of the congenital cataract. Cataract extraction can relieve the form deprivation of the affected eye and increase the vessel density at the posterior pole of the affected eye significantly.

Keywords: unilateral congenital cataract, OCTA, cataract extraction, vessel density, form deprivation

\section{Introduction}

Congenital cataract is the leading cause of visual disorders and blindness in children because the associated early form deprivation can seriously affect the development of the visual nervous system. ${ }^{1}$ In children with unilateral congenital cataract, the contralateral eye's visual acuity is generally normal and the ability to cooperate with the examination is poor, thus early diagnosis is relatively difficult. Therefore, the diagnosis occurs relatively late, and visual acuity after cataract extraction is not perfect. The form deprivation caused by unilateral congenital cataract is complicated and the pathogenesis remains unclear. Previous studies have shown that the thickness of the retinal nerve fiber layer (RNFL) and central area of the macula lutea of asthenopic eyes with form deprivation after unilateral 
congenital cataract surgery is thicker than that of the normal non-amblyopic eye. Abnormalities may exist in the structure of the retina, ${ }^{2}$ but change of the vessel density of the optic disc and macular area has not been reported. In this study, we compared the optical coherence tomography angiography (OCTA) results of patients who underwent unilateral congenital cataract surgery at our hospital before and after surgery to explore the pathogenesis of unilateral congenital cataract and to provide a basis for the early diagnosis and treatment of the disease.

\section{Materials and Methods}

\section{Participants}

Children with unilateral congenital cataract and formdeprivation amblyopia were included in our study in Department of Ophthalmology, from September 2015 to December 2019. The inclusion criteria were: 1. Single-eye congenital cataract with amblyopia; 2 . The logMAR best corrected visual acuity (BCVA) of the affected eye less than $0.3 ; 3$. No other organic diseases of the eye and visual pathway. The exclusion criteria were: 1 . Patients with other eye diseases in addition to congenital cataract; 2 . Patients who could not cooperate with eye examinations; 3 . Patients who could not cooperate with follow-up. This study was approved by the ethics committee of the First Affiliated Hospital with Nanjing Medical University, and conformed to the tenets of the Declaration of Helsinki. We confirm that a parent or legal guardian provided written informed consent for participation of children in this study. Patients were divided into three groups: the contralateral cataract-free eyes of the patient were used as the normal control group, the cataract eyes before surgery were assigned into the preoperative group, and the eyes that underwent surgerywere assigned into postoperative group.

\section{Surgical Procedures}

All of the children included in the study had undergone systematic ocular examination before surgery, including BCVA before and after surgery, intraocular pressure analysis, slit lamp examination, ocular A/B ultrasonography, direct/ indirect ophthalmoscopy, and fundus photographic examination. The fundus density before and after surgery was examined using the Angio-OCT system (Opotvue, USA, Avanti RTVue XR, longitudinal resolution $=5 \mu \mathrm{m}$, lateral resolution $=3$ $\mu \mathrm{m}$, scan rate $=70,000$ times/second). The compound tropicamide was required for mydriasis before the patient was examined. The cataract extraction procedure was performed as follows: lensectomy with general anesthesia + continuous posterior balloon avulsion + anterior vitrectomy + intraocular lens implantation. All of the operations were performed by the same surgeon. The implanted intraocular lens was the Alcon SN60WF intraocular lens. All of the patients underwent surgery successfully, with a follow-up visit at one month after surgery.

\section{Optical Coherence Tomography Angiography}

The parameters of Angio-OCT were set to scan in the $6.0 \mathrm{~mm} * 6.0 \mathrm{~mm}$ scanning mode of the macular arch area. The vessel density of the superficial layer around the macular area was calculated by the system's vascular density analysis function. The corresponding area retinal thicknesses were also recorded. ${ }^{3}$ Optic disc scanning in angio-disc mode was used to scan the optic disc in the range of $4.5 \mathrm{~mm} * 4.5 \mathrm{~mm}$, analyzing the small vessel density of radial peripapillary capillaries (RPC) and the RNFL thickness. ${ }^{4}$ All of the examinations were performed by the same fundus doctor.

\section{Statistical Analysis}

Statistical analysis was performed using SPSS 17.0 software. The measurement data were expressed as means \pm standard deviation $(\overline{\mathrm{x}} \pm \mathrm{s})$. Comparison between groups was performed by one-way analysis of variance, and pairwise comparison was performed by $t$-test. $\mathrm{p}<0.05$ was considered statistically significant.

\section{Results}

\section{Comparison of Basic Data Between Patients}

There were 35 patients included in our study. The cases comprised 19 males and 16 females aged 3 13 (7.37 $\pm 3.07)$ years. We compared the differences between the eyes before surgery, after surgery and the normal control eyes according to the BCVA, intraocular pressure, change in the axial length and corneal refractive power (Table 1). We foundthat one month after surgery the BCVA was significantly improved compared with that before surgery $(t=5.179, p<0.001)$. The axial length was also changed one month after surgery $(\mathrm{t}=5.350, \mathrm{p}<0.001)$. There was no significant statistical difference in the IOP between the two groups $(\mathrm{t}=1.424, \mathrm{p}=0.159)$. 
Table I Basic Information of the Patients in the Three Groups

\begin{tabular}{|l|l|l|l|l|l|}
\hline Index & Preoperation & One Month After Surgery & Normal Control & F & P \\
\hline Number of eyes & 35 & 35 & 35 & \\
Sex (Male) & 19 & 19 & 19 & 0.151 & 0.860 \\
Age & $7.23 \pm 3.08$ & $7.23 \pm 3.08$ & $7.51 \pm 3.09$ & 0.1 & 0.905 \\
BCVA (logMAR) & $1.06 \pm 0.31$ & $0.64 \pm 0.35$ & $-0.03 \pm 0.15$ & 129.76 & 0.000 \\
Intraocular pressure (IOP) & $16.37 \pm 3.07$ & $15.31 \pm 3.14$ & $15.79 \pm 3.11$ & 1.04 & 0.357 \\
Eye axial length & $23.21 \pm 0.27$ & $22.83 \pm 0.33$ & $22.51 \pm 0.21$ & 59.11 & 0.000 \\
\hline
\end{tabular}

\section{Comparison of the Superficial Vessel Density and Retina Thickness Around the Macular Area}

The superficial vessel density of the macular area was divided into three parts: fovea, parafovea and perifovea. Each part was divided into four sections in the last two parts. The changes of vascular density in each section were compared (Table 2). The results showed significant differences in vessel density between the ill eyes and normal control eyes (Figure 1). A partial improvement was observed in the first month after surgery, and the difference in retinal thickness in the three groups also changed.

\section{Comparison of the RPC Small Vessel Density and RNFL Thickness}

The small vessel density of the RPC layers of the three groups was divided into eight sections, and the changes in peripapillary vessel density in each section were compared (Table 3 ). Table 4 shows the changes of vessel density and thickness between preoperation and postoperation groups using a paired $t$-test. Figure 2 shows the differences in vessel density and retinal thickness between the three groups. The results show that the average vessel density in the cataract eye was significantly lower than the normal eye $(\mathrm{t}=-7.465, \mathrm{p}<0.001)$, but was not significantly

Table 2 Superficial Vessel Density and Thickness in the Macular Area Between the Three Groups

\begin{tabular}{|c|c|c|c|c|c|}
\hline Macular Vessel Density & Preoperation & One Month After Surgery & Normal Control Eye & $\mathbf{F}$ & p value \\
\hline \multicolumn{6}{|l|}{ Superficial vessel } \\
\hline Fovea & $20.1 I \pm 1.6 I$ & $22.14 \pm 1.79$ & $23.97 \pm 1.95$ & 40.92 & 0.000 \\
\hline ParaFovea & $46.03 \pm 2.98$ & $48.80 \pm 2.70$ & $52.97 \pm 2.09$ & 62.51 & 0.000 \\
\hline Tempo & $48.20 \pm 3.40$ & $50.74 \pm 2.86$ & $53.91 \pm 1.88$ & 36.90 & 0.000 \\
\hline Superior & $47.77 \pm 2.33$ & $51.17 \pm 3.36$ & $54.97 \pm 1.77$ & 68.71 & 0.000 \\
\hline Nasal & $48.20 \pm 3.06$ & $50.49 \pm 1.76$ & $54.97 \pm 1.25$ & 89.13 & 0.000 \\
\hline Inferior & $45.14 \pm 3.11$ & $49.57 \pm 3.00$ & $56.66 \pm 1.08$ & 179.01 & 0.000 \\
\hline PeriFovea & $46.89 \pm 2.44$ & $51.03 \pm 2.02$ & $52.51 \pm 1.46$ & 73.50 & 0.000 \\
\hline Tempo & $44.63 \pm 2.00$ & $45.94 \pm 2.53$ & $49.34 \pm 1.86$ & 44.77 & 0.000 \\
\hline Superior & $46.06 \pm 3.07$ & $48.00 \pm 2.28$ & $53.49 \pm 2.05$ & 82.97 & 0.000 \\
\hline Nasal & $48.74 \pm 3.94$ & $52.03 \pm 2.40$ & $56.77 \pm 1.14$ & 75.94 & 0.000 \\
\hline Inferior & $45.20 \pm 2.75$ & $49.11 \pm 2.83$ & $54.06 \pm 1.70$ & 112.17 & 0.000 \\
\hline \multicolumn{6}{|l|}{ Thickness } \\
\hline Fovea & $233.80 \pm 4.05$ & $234.94 \pm 3.60$ & $250.20 \pm 3.43$ & 214.24 & 0.000 \\
\hline ParaFovea & $30|.20 \pm| 1.5 \mid$ & $298.37 \pm 22.52$ & $322.34 \pm 6.75$ & 58.00 & 0.000 \\
\hline Tempo & $298.20 \pm$ II.II & $295.66 \pm 10.03$ & $309.94 \pm 9.64$ & 19.24 & 0.000 \\
\hline Superior & $305.54 \pm 11.82$ & $305.09 \pm 10.23$ & $318.63 \pm 12.40$ & 15.59 & 0.000 \\
\hline Nasal & $295.43 \pm 10.89$ & $295.29 \pm 11.52$ & $318.63 \pm 10.52$ & 52.41 & 0.000 \\
\hline Inferior & $304.7 I \pm 9.8 I$ & $305.89 \pm 8.81$ & $321.37 \pm 3.59$ & 48.58 & 0.000 \\
\hline PeriFovea & $261.97 \pm 4.24$ & $263.11 \pm 4.83$ & $278.54 \pm 6.90$ & 101.15 & 0.000 \\
\hline Tempo & $260.29 \pm 8.12$ & $263.09 \pm 7.82$ & $269.31 \pm 6.14$ & 13.60 & 0.000 \\
\hline Superior & $265.7 I \pm 8.58$ & $264.46 \pm 9.52$ & $283.06 \pm 5.96$ & 56.81 & 0.000 \\
\hline Nasal & $265.57 \pm 10.98$ & $269.57 \pm 11.24$ & $295.66 \pm 10.73$ & 77.45 & 0.000 \\
\hline Inferior & $260.51 \pm 9.86$ & $260.54 \pm 7.56$ & $276.7| \pm 8.4|$ & 40.74 & 0.000 \\
\hline
\end{tabular}




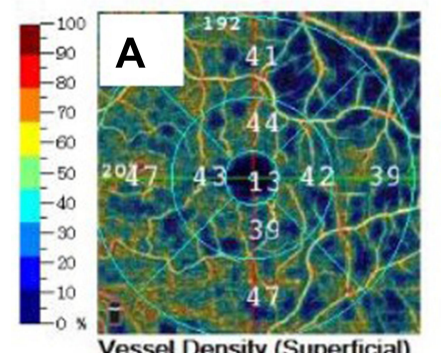

Vessel Density (Superficial)
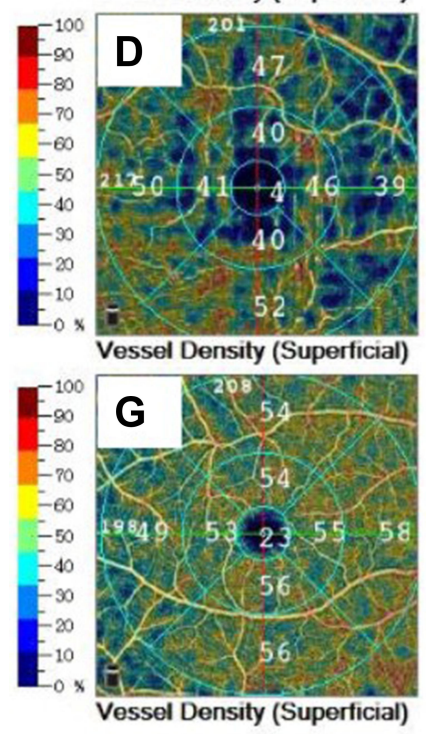

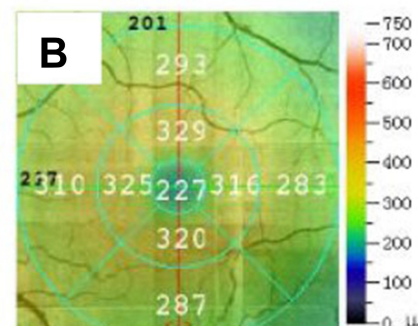

Full Thickness (ILM - RPE)

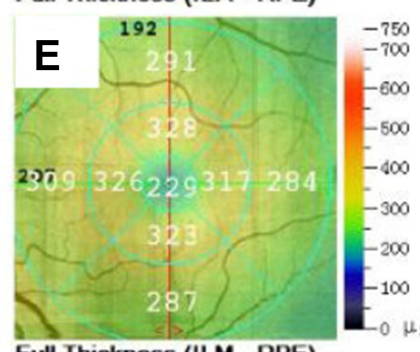

Full Thickness (ILM - RPE)

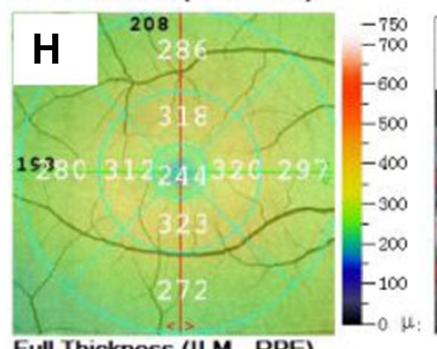

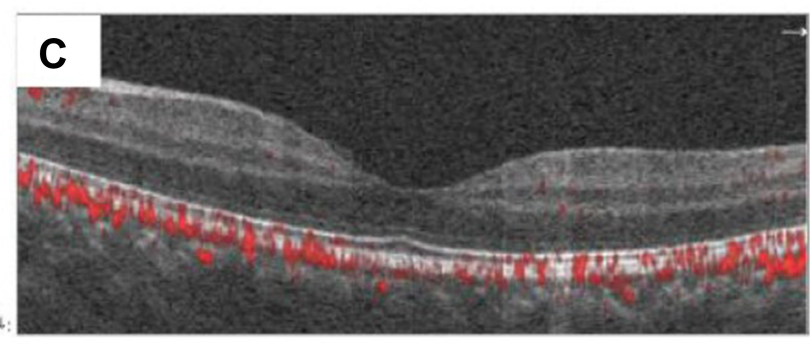
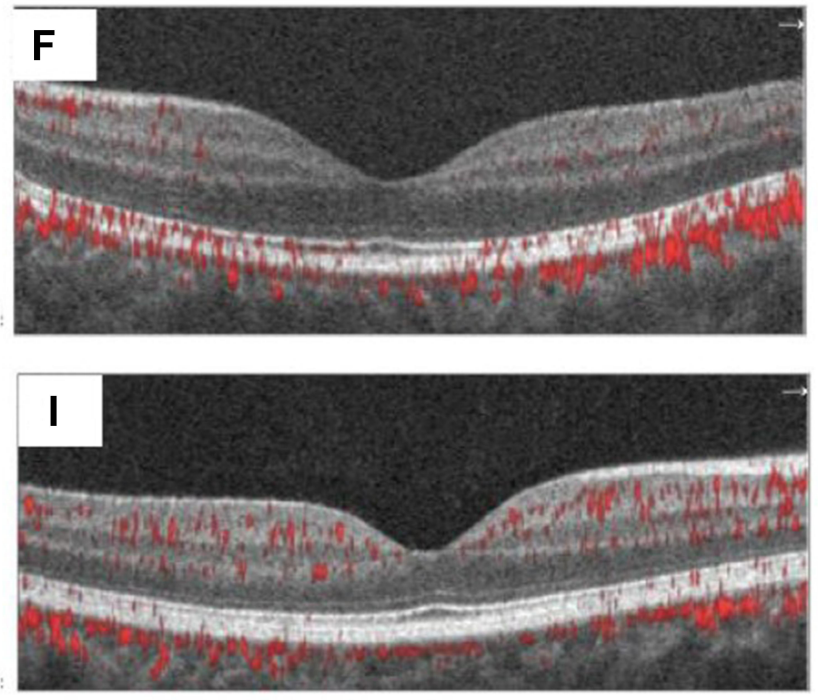

Figure I The superficial vessels density and retinal thickness of macular area in different groups. (A) superficial vessel density before operation, (B) full reinal thickness before operation, (C) structure and blood flow of macular area before operation; (D) superficial vessel density at I month after surgery, (E) full reinal thickness at I month after surgery, (F) structure and blood flow of macular area at I month after surgery; (G) superficial vessel density in normal control eye, (H) full reinal thickness in normal control eye, (I) structure and blood flow of macular area in normal control eye.

improved one month after surgery $(\mathrm{t}=-1.493, \mathrm{p}=0.14)$, except for Nasal Inferior part, Tempo Superior part, Superior Tempo and Superior Nasal part. For the RNFL thickness, the average thickness was not significantly changed after surgery $(\mathrm{t}=-0.472, \mathrm{p}=0.671)$. There was no significant difference in the average thickness between the three groups.

\section{Discussion}

As a noninvasive fundus angiography method, OCTA can accurately analyze the vessel densities in the optic disc and macular area, providing a basis for the diagnosis and treatment of ophthalmic diseases and prognosis evaluation. ${ }^{5}$ A previous study showed that abnormal retinal neuroepithelium layer thickness of the optic disc and macular area in eyes with unilateral congenital cataract may be an underlying cause of this disease. ${ }^{2}$ Our study first used OCTA to detect the vessel density in the optic disc and macular area of eyes with unilateral congenital cataract, and our results indicated that the vascular density of the macular area and optic disc of the affected eye was significantly lower than that of the normal eye. Additionally, the vessel density and retina thickness of the macular area were significantly improved after cataract extraction surgery compared with before surgery. However, the average thickness of RNFL showed no obvious distinction between three groups.

The cause of unilateral congenital cataract is complicated, and its pathogenesis remain unclear. Our study found that in all eyes with unilateral congenital cataract, the vessel density in the macular area and optic disc area is significantly lower than that in the normal control eye. Thus, we infer that the decrease in vascular density in the fundus posterior pole may be an underlying cause of vision loss and cataract. The currently accepted treatment for congenital cataract is early surgery to ensure transparency of the refractive medium and optical correction as soon as possible. ${ }^{6}$ In our study, after the cataract was found, lensectomy and intraocular lens implantation were performed in time. 
Table 3 RPC Layer Small Vessel Density and RNFL Thickness Between the Three Groups

\begin{tabular}{|c|c|c|c|c|c|}
\hline Optic Disc Blood Vessel Density & Preoperation & One Month After Surgery & Normal Control Eye & $\mathbf{F}$ & p value \\
\hline \multicolumn{6}{|l|}{ RPC small vessels density } \\
\hline Peripapillary & $43.23 \pm 2.98$ & $44.31 \pm 3.10$ & $48.20 \pm 2.58$ & 28.52 & 0.000 \\
\hline Nasal Superior & $43.11 \pm 3.10$ & $43.3 I \pm 2.93$ & $48.09 \pm 1.93$ & 36.83 & 0.000 \\
\hline Nasal Inferior & $40.34 \pm 4.93$ & $45.86 \pm 3.41$ & $45.83 \pm 3.37$ & 22.40 & 0.000 \\
\hline Inferior Nasal & $44.7 I \pm 5.3 I$ & $45.34 \pm 4.36$ & $50.29 \pm 2.49$ & 18.32 & 0.000 \\
\hline Inferior Tempo & $47.97 \pm 6.39$ & $45.91 \pm 5.08$ & $53.71 \pm 4.91$ & 18.92 & 0.000 \\
\hline Tempo Inferior & $46.69 \pm 2.23$ & $46.97 \pm 3.75$ & $55.00 \pm 2.96$ & 84.20 & 0.000 \\
\hline Tempo Superior & $48.66 \pm 2.44$ & $50.03 \pm 1.89$ & $55.43 \pm 2.13$ & 95.83 & 0.000 \\
\hline Superior Tempo & $53.20 \pm 2.29$ & $52.17 \pm 1.47$ & $55.77 \pm 3.12$ & 21.14 & 0.000 \\
\hline Superior Nasal & $49.00 \pm 3.48$ & $51.26 \pm 3.42$ & $54.66 \pm 3.15$ & 25.21 & 0.000 \\
\hline \multicolumn{6}{|l|}{ RNFL thickness } \\
\hline Peripapillary & || $5.74 \pm 5.7 \mid$ & $116.34 \pm 6.06$ & $116.89 \pm 5.45$ & 0.35 & 0.708 \\
\hline Nasal Superior & $|10.29 \pm 8.6|$ & $109.14 \pm 8.35$ & $114.80 \pm 10.46$ & 3.71 & 0.028 \\
\hline Nasal Inferior & $97.77 \pm 6.67$ & $100.03 \pm 7.53$ & $99.34 \pm 7.88$ & 0.86 & 0.426 \\
\hline Inferior Nasal & $113.63 \pm 10.67$ & || $6.54 \pm|| .87$ & $116.97 \pm 10.76$ & 0.94 & 0.40 \\
\hline Inferior Tempo & $|56.46 \pm| \mid .33$ & $158.09 \pm 9.27$ & $157.46 \pm 12.14$ & 0.20 & 0.822 \\
\hline Tempo Inferior & $78.46 \pm 7.18$ & $76.11 \pm 8.16$ & $78.43 \pm 9.86$ & 0.881 & 0.417 \\
\hline Tempo Superior & $66.94 \pm 11.27$ & $71.37 \pm 10.78$ & $68.40 \pm 11.70$ & 1.41 & 0.249 \\
\hline Superior Tempo & $122.40 \pm 14.15$ & $127.17 \pm 12.45$ & $|2| .89 \pm 13.83$ & 1.63 & 0.20 \\
\hline Superior Nasal & $150.23 \pm 11.39$ & $150.69 \pm 11.10$ & $152.60 \pm 10.97$ & 0.445 & 0.642 \\
\hline
\end{tabular}

The postoperative visual acuity of the affected eye was significantly improved compared with the preoperative visual acuity. Compared with the normal control eye, although the postoperative visual acuity of the affected eye was still amblyopic, the surgery had already maintained the transparency of the refractive axis of the affected eye. Continuous amblyopia training is expected to improve the eyesight of the affected eye. Additionally, we found that after cataract extraction surgery, the vascular density in the macular area and optic disc area of the affected eye was significantly improved compared with that preoperatively, which suggested that after the form deprivation of the affected eye was relieved, the refractive axis of the affected eye became transparent, leading to increased stimulation of optical signals entering the eye, after which the fundus structure would change accordingly. With increased retinal vascular density, optic nerve stimulation may be further developed, significantly improving visual acuity compared with that preoperatively.

Early form deprivation is considered a major obstacle to vision development. Additionally, abnormal axis oculi development is a cause of low vision in congenital cataracts. ${ }^{7}$ A study showed that the axis oculi of children with unilateral congenital cataracts less than
18 months of age was shorter than that of the normal eye; with prolongation of form deprivation, the axis oculi of the affected eye was gradually prolonged and grew significantly compared with that of the normal eye. ${ }^{8}$ According to our findings, the axis oculi of the affected eye was longer than that of the normal eye, and the difference was statistically significant. One month after cataract extraction, the axial length of the eye was gradually tending towards that of the normal eye. Thus, the development of the axial length in children's eyes may gradually become normal if the form deprivation of the affected eye can be released as soon as possible.

The choice of timing for unilateral congenital cataract surgery is crucial for visual rehabilitation of children. Early treatment is the key to achieving a good prognosis. Studies have recommended that surgery should be performed within 2 years of age before the critical period of visual development, while others have recommended that surgical treatment should be performed within 6 months after birth. ${ }^{9,10}$ The sooner the form deprivation is released, the more favorable it is for the eye to obtain good vision and then establish binocular stereo vision. ${ }^{11,12}$ OCTA can objectively reflect the retinal blood flow and vascular density of 
Table 4 Paired $t$-Test of Superficial Vessel Density and Thickness in the Macular Area, RPC Layer Small Vessel Density and RNFL Thickness Before and One Month After Surgery

\begin{tabular}{|c|c|c|c|c|}
\hline Paired $t$-Test & Preoperation & One Month After Surgery & $\mathbf{t}$ & p value \\
\hline BCVA (logMAR) & $1.06 \pm 0.31$ & $0.64 \pm 0.35$ & 4.87 & 0.000 \\
\hline Intraocular pressure (IOP) & $16.37 \pm 3.07$ & $|5.3| \pm 3.14$ & 1.42 & 0.164 \\
\hline Eye axial length & $23.2 I \pm 0.27$ & $22.83 \pm 0.33$ & 5.27 & 0.000 \\
\hline \multicolumn{5}{|l|}{ Macular surperficial vessel } \\
\hline Fovea & $20.11 \pm 1.61$ & $22.14 \pm 1.79$ & -4.84 & 0.000 \\
\hline ParaFovea & $46.03 \pm 2.98$ & $48.80 \pm 2.70$ & -4.66 & 0.000 \\
\hline Tempo & $48.20 \pm 3.40$ & $50.74 \pm 2.86$ & -3.59 & 0.001 \\
\hline Superior & $47.77 \pm 2.33$ & $51.17 \pm 3.36$ & -4.84 & 0.000 \\
\hline Nasal & $48.20 \pm 3.06$ & $50.49 \pm 1.76$ & -3.95 & 0.000 \\
\hline Inferior & $45.14 \pm 3.11$ & $49.57 \pm 3.00$ & -6.94 & 0.000 \\
\hline PeriFovea & $46.89 \pm 2.44$ & $51.03 \pm 2.02$ & -7.41 & 0.000 \\
\hline Tempo & $44.63 \pm 2.00$ & $45.94 \pm 2.53$ & -2.54 & 0.016 \\
\hline Superior & $46.06 \pm 3.07$ & $48.00 \pm 2.28$ & -2.98 & 0.005 \\
\hline Nasal & $48.74 \pm 3.94$ & $52.03 \pm 2.40$ & -3.89 & 0.000 \\
\hline Inferior & $45.20 \pm 2.75$ & $49.11 \pm 2.83$ & -5.99 & 0.000 \\
\hline \multicolumn{5}{|l|}{ Macular Thickness } \\
\hline Fovea & $233.80 \pm 4.05$ & $234.94 \pm 3.60$ & -1.17 & 0.251 \\
\hline ParaFovea & $30|.20 \pm||.5|$ & $298.37 \pm 22.52$ & 1.13 & 0.266 \\
\hline Tempo & $298.20 \pm 11.11$ & $295.66 \pm 10.03$ & 0.885 & 0.383 \\
\hline Superior & $305.54 \pm \mid I .82$ & $305.09 \pm 10.23$ & 0.16 & 0.872 \\
\hline Nasal & $295.43 \pm 10.89$ & $295.29 \pm 11.52$ & 0.06 & 0.956 \\
\hline Inferior & $304.71 \pm 9.81$ & $305.89 \pm 8.81$ & -0.49 & 0.626 \\
\hline PeriFovea & $261.97 \pm 4.24$ & $263.11 \pm 4.83$ & -1.01 & 0.322 \\
\hline Tempo & $260.29 \pm 8.12$ & $263.09 \pm 7.82$ & -1.46 & 0.154 \\
\hline Superior & $265.71 \pm 8.58$ & $264.46 \pm 9.52$ & 0.58 & 0.567 \\
\hline Nasal & $265.57 \pm 10.98$ & $269.57 \pm I \mid .24$ & -1.46 & 0.153 \\
\hline Inferior & $260.51 \pm 9.86$ & $260.54 \pm 7.56$ & -0.01 & 0.990 \\
\hline \multicolumn{5}{|l|}{ RPC small vessels density } \\
\hline Peripapillary & $43.23 \pm 2.98$ & $44.31 \pm 3.10$ & $-|.5|$ & 0.141 \\
\hline Nasal Superior & $43.11 \pm 3.10$ & $43.31 \pm 2.93$ & -0.27 & 0.788 \\
\hline Nasal Inferior & $40.34 \pm 4.93$ & $45.86 \pm 3.41$ & -7.25 & 0.000 \\
\hline Inferior Nasal & $44.7 I \pm 5.3 I$ & $45.34 \pm 4.36$ & -0.56 & 0.582 \\
\hline Inferior Tempo & $47.97 \pm 6.39$ & $45.91 \pm 5.08$ & 1.35 & 0.184 \\
\hline Tempo Inferior & $46.69 \pm 2.23$ & $46.97 \pm 3.75$ & -0.36 & 0.722 \\
\hline Tempo Superior & $48.66 \pm 2.44$ & $50.03 \pm 1.89$ & -2.76 & 0.009 \\
\hline Superior Tempo & $53.20 \pm 2.29$ & $52.17 \pm 1.47$ & 2.20 & 0.034 \\
\hline Superior Nasal & $49.00 \pm 3.48$ & $51.26 \pm 3.42$ & -2.90 & 0.007 \\
\hline \multicolumn{5}{|l|}{ RNFL thickness } \\
\hline Peripapillary & || $5.74 \pm 5.7 \mid$ & $116.34 \pm 6.06$ & -0.49 & 0.630 \\
\hline Nasal Superior & || $0.29 \pm 8.6 \mid$ & $109.14 \pm 8.35$ & 0.59 & 0.560 \\
\hline Nasal Inferior & $97.77 \pm 6.67$ & $100.03 \pm 7.53$ & -1.44 & 0.158 \\
\hline Inferior Nasal & $113.63 \pm 10.67$ & || $6.54 \pm|| .87$ & -1.11 & 0.274 \\
\hline Inferior Tempo & $|56.46 \pm| \mid .33$ & $158.09 \pm 9.27$ & -0.66 & 0.512 \\
\hline Tempo Inferior & $78.46 \pm 7.18$ & $76.11 \pm 8.16$ & 1.38 & 0.177 \\
\hline Tempo Superior & $66.94 \pm 11.27$ & $71.37 \pm 10.78$ & -1.76 & 0.088 \\
\hline Superior Tempo & $122.40 \pm 14.15$ & $127.17 \pm 12.45$ & -1.35 & 0.187 \\
\hline Superior Nasal & $|50.23 \pm| \mid .39$ & $150.69 \pm 1 \mid .10$ & -0.15 & 0.878 \\
\hline
\end{tabular}



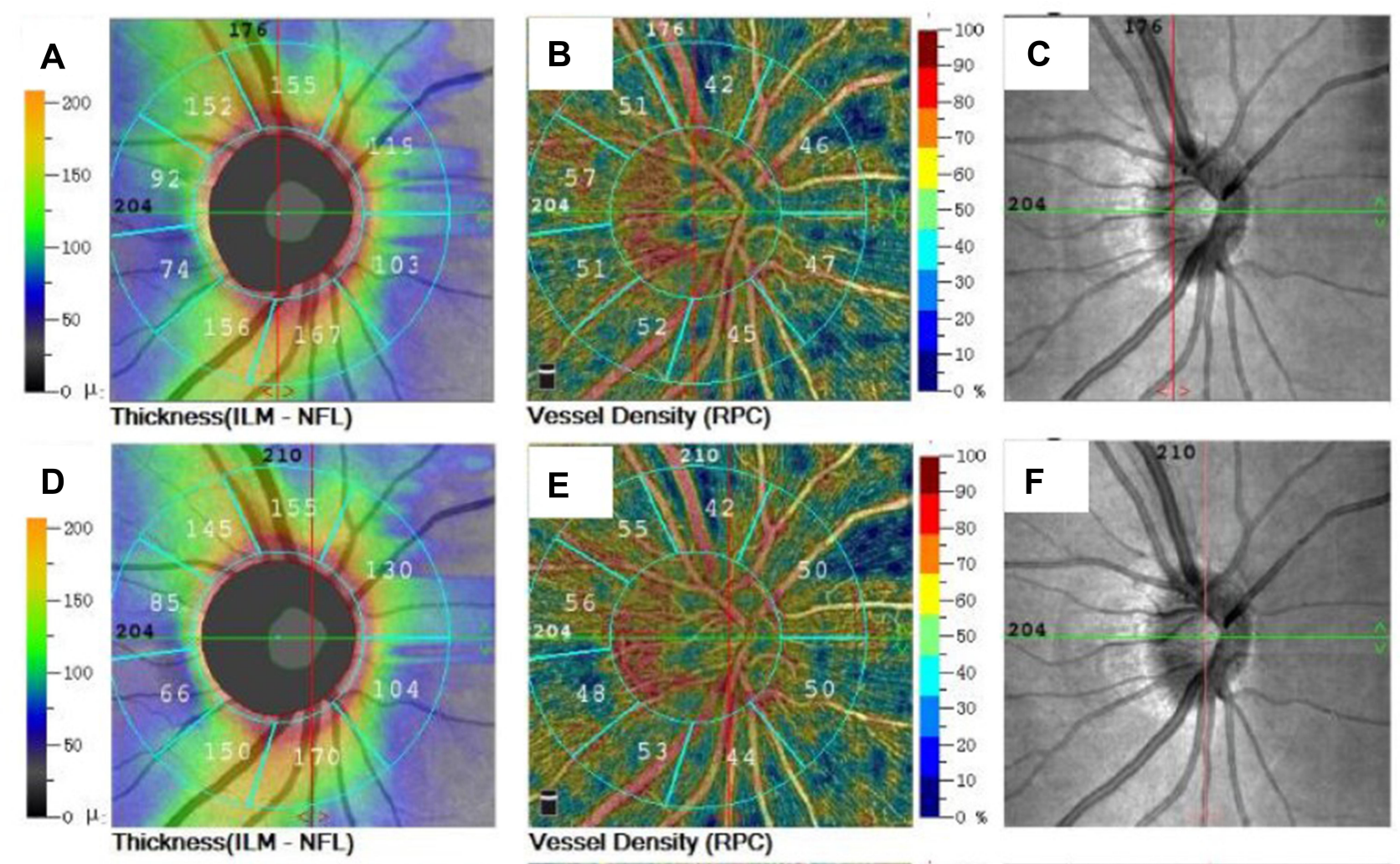

Vessel Density (RPC)
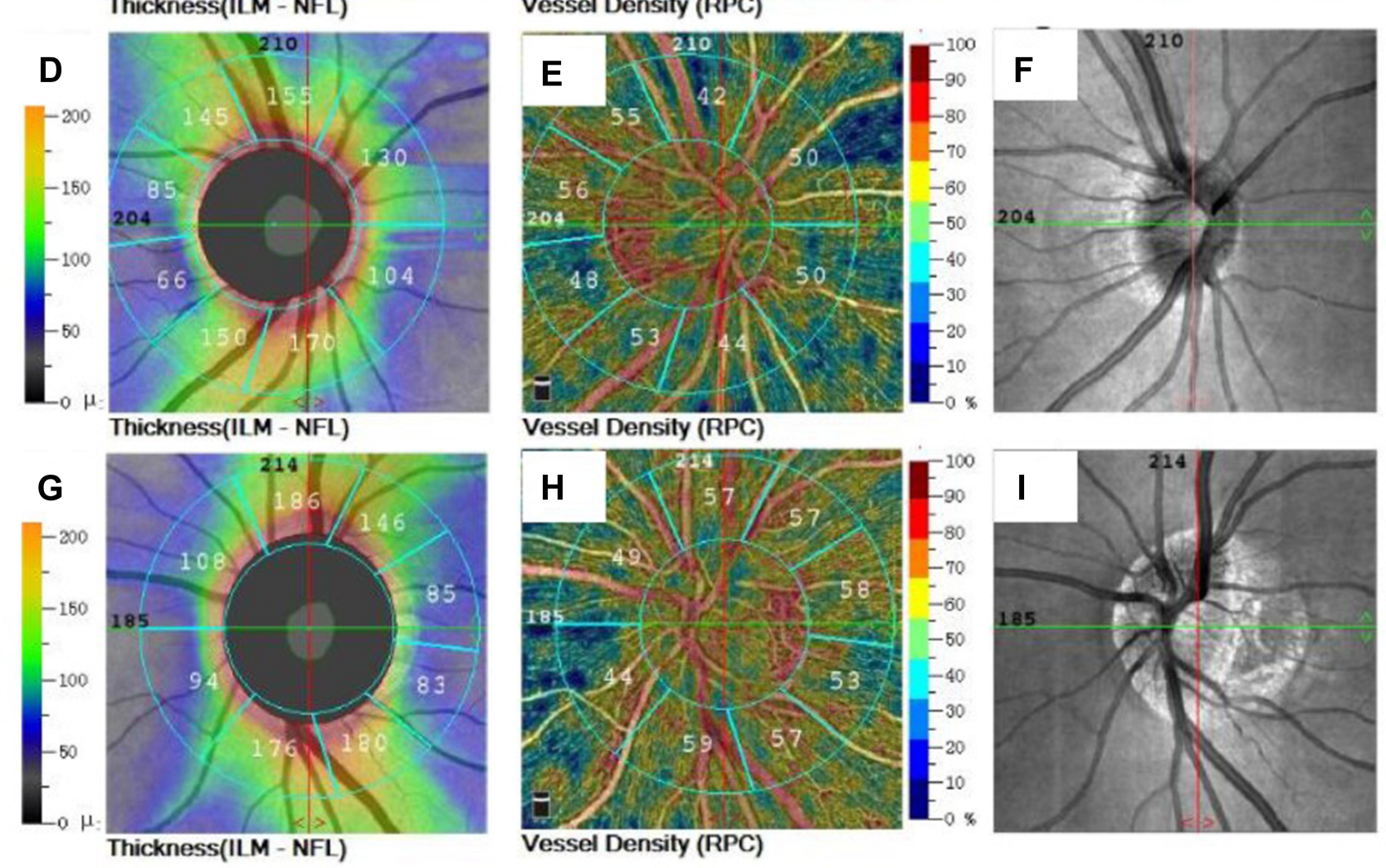

Figure 2 The RPC vessel density and peripapillary thickness of optic disc in different groups. (A) Peripapillary thickness of optic disc before operation, (B) RPC vessel density before operation, (C) scanning laser fundus image of optic disc before operation, (D) peripapillary thickness of optic disc at I month after surgery, (E) RPC vessel density at I month after surgery, (F) scanning laser fundus image of optic disc at I month after surgery; (G) peripapillary thickness of optic disc in normal control eye, (H) RPC vessel density in normal control eye, (I) scanning laser fundus image of optic disc in normal control eye.

Abbreviation: RPC, radial peripapillary capillaries.

the eye. The method is simple and can play a role in evaluating and predicting the visual function after cataract extraction, facilitating the timely and effective adjustment of the patient's postoperative rehabilitation treatment plan. However, the sample size of this study was relatively small, and the postoperative follow-up time was short. Therefore, changes in vessel density after unilateral congenital cataract extraction require further study, with the inclusion of more samples and extension of the observation and follow-up times.

\section{Conclusion}

In summary, unilateral congenital cataract should be removed as soon as possible, to significantly improve the visual acuity of the affected eye and increase the ocular density of the fundus macular and optic disc. OCTA can objectively evaluate the blood flow and vessel density of the fundus of eyes with unilateral congenital cataract, providing a basis for evaluating and predicting visual function after surgery and facilitating the adjustment of treatment for patients with unilateral congenital cataract. 


\section{Ethics and Consent Statement}

This study was approved by the ethics committee of the First Affiliated Hospital of Nanjing Medical University, and conformed to the tenets of the Declaration of Helsinki and written informed consent was obtained from all parents or caregivers.

\section{Author Contributions}

Weiwei Zhang, Huan $\mathrm{Hu}$, and Haixia Cheng are co-first authors and they contributed equally in this study. W.Z., H. H. and H.X.C. have contributed to the conception and design, acquisition of data, analysis and interpretation of data, and drafting the manuscript. Q.H.L. has contributed to the acquisition of data, analysis and interpretation of data, and drafting the manuscript. D.Q.Y. has contributed to the conception and design, acquisition of data, analysis and interpretation of data, and critically reviewing the manuscript. All authors made substantial contributions to conception and design, acquisition of data, or analysis and interpretation of data; took part in drafting the article or revising it critically for important intellectual content; agreed to submit to the current journal; gave final approval of the version to be published; and agree to be accountable for all aspects of the work.

\section{Funding}

This research project was supported by Natural Science Foundation of Jiangsu Province (No. BK20191497). The funders had no role in study design, data collection and analysis, decision to publish, or preparation of the manuscript.

\section{Disclosure}

The authors have no conflicts of interest to declare.

\section{References}

1. Fox A, O'Keefe M, Lanigan B. A follow-on study on vision-related quality of life assessment using the NEI-VFQ-25 in those with a history of unilateral and bilateral congenital cataracts. Acta Ophthalmol. 2018;96(5):e596-e599. doi:10.1111/aos.13692

2. Bansal P, Ram J, Sukhija J, et al. Retinal nerve fiber layer and macular thickness measurements in children after cataract surgery compared with age-matched controls. Am $J$ Ophthalmol. 2016;166:126-132. doi:10.1016/j.ajo.2016.03.041

3. Brás JEG, Sickenberger W, Hirnschall N, et al. Cataract quantification using swept-source optical coherence tomography. J Cataract Refract Surg. 2018;44(12):1478-1481. doi:10.1016/j.jcrs.2018.08.009

4. Yu S, Frueh BE, Steinmair D, et al. Cataract significantly influences quantitative measurements on swept-source optical coherence tomography angiography imaging. PLoS One. 2018;13(10):e0204501. doi:10.1371/journal.pone.0204501

5. Wang L, Murphy O, Caldito NG, et al. Emerging applications of Optical Coherence Tomography Angiography (OCTA) in neurological research. Eye Vis. 2018;5(1):11. doi:10.1186/s40662-018-0104-3

6. Qi JY, Xiao W, Wang MY, et al. Long-term outcomes after cataract surgery in infants with congenital cataract. Zhonghua Yan Ke Za Zhi. 2017;53(4):266-273.

7. Khokhar S, Jose CP, Sihota R, et al. Unilateral congenital cataract: clinical profile and presentation. J Pediatr Ophthalmol Strabismus. 2018;55(2):107-112. doi:10.3928/01913913-20170703-11

8. Tadros D, Trivedi RH, Wilson ME, et al. Ocular axial growth in pseudophakic eyes of patients operated for monocular infantile cataract: a comparison of operated and fellow eyes measured at surgery and 5 or more years later. $J$ AAPOS. 2016;20(3):210-213. doi:10.1016/j.jaapos.2016.01.011

9. Solebo AL, Cumberland P, Rahi JS, et al. 5-year outcomes after primary intraocular lens implantation in children aged 2 years or younger with congenital or infantile cataract: findings from the IoLunder2 prospective inception cohort study. Lancet Child Adolesc Health. 2018;2(12):863-871. doi:10.1016/S2352-4642(18)30317-1

10. Negalur M, Sachdeva V, Neriyanuri S, et al. Long-term outcomes following primary intraocular lens implantation in infants younger than 6 months. Indian $J$ Ophthalmol. 2018;66(8):1088-1093. doi:10.4103/ijo.IJO_182_18

11. Sarfare S, Yang J, Nickla DL. The effects of brief high intensity light on ocular growth in chick eyes developing myopia vary with time of day. Exp Eye Res. 2020;108039.

12. Zi Y, Deng Y, Zhao J, et al. Morphologic and biochemical changes in the retina and sclera induced by form deprivation high myopia in guinea pigs. BMC Ophthalmol. 2020;20(1):105. doi:10.1186/s12886020-01377-1
Clinical Ophthalmology

\section{Publish your work in this journal}

Clinical Ophthalmology is an international, peer-reviewed journal covering all subspecialties within ophthalmology. Key topics include: Optometry; Visual science; Pharmacology and drug therapy in eye diseases; Basic Sciences; Primary and Secondary eye care; Patient Safety and Quality of Care Improvements. This journal is indexed on PubMed
Central and CAS, and is the official journal of The Society of Clinical Ophthalmology (SCO). The manuscript management system is completely online and includes a very quick and fair peer-review system, which is all easy to use. Visit http://www.dovepress.com/ testimonials.php to read real quotes from published authors.

\section{Dovepress}

